Annals of Plant and Soil Research 22(4): 367-372 (2020)

https://doi.org/10.47815/apsr.2020.10006

\title{
Land capability assessment of Ghaggar river basin using integrated remote sensing and geographical information system approach - A Case Study
}

\author{
NITIN CHAUHAN ${ }^{*}$, VIPIN KUMAR AND RAKESH PALIWAL ${ }^{1}$
}

\author{
School of Earth Science, Banasthali University, Newai, Tonk, Rajasthan-304022
}

Received: July, 2020; Revised accepted: August, 2020

\begin{abstract}
The increased anthropogenic activities lead to reduction of the actual as well as potential agricultural productivity by intensifying the land degradation process. Therefore, mismatch arises between the capability of a land and landuse due to this land degradation. The present study was carried out to classify the Ghaggar river basin area as per its capabilities at Banasthali University during 2020. The slope, soil depth, texture, drainage conditions, stoniness and the extent of erosion were used to assess the land capability. The analysis resulted in the presence of seven land capability classes (I-IV and VI-VIII) in the Ghaggar river basin. The areal distribution of the arable (I to IV) and non-arable (VI to VIII) land capability classes within the study area was 51.9 and 48.1 $\%$, respectively. The individual distribution of the area under I, II, III, IV, VI, VII and VIII land capability classes were 14.9, 15.2,9.3,12.6,26.7,20.5and 0.9\%, respectively. Although the agricultural activities are recommended in the capability classes I to IV but about $47.1 \%$ of the agricultural activities are also extended in the VI to VIII capability classes. On the contrary, land use classes such as built-up, shrub-land, forest, etc. were present in I to IV classes which were capable for annual crop cultivation.
\end{abstract}

Keywords: Land capability, geographical information system, Ghaggar, Shivaliks

\section{INTRODUCTION}

The ever-growing population is exerting tremendous pressure on the natural resources due to increase in competition for various demands. The sustainable management of the natural resources is very important so that they can meet the current demands without fading the potential for future use. Land resource is severely degraded globally due to anthropogenic activities like, mismanaged agriculture, deforestation, industrialization. In India $29.3 \%$ of the total geographical area equivalent to 96.43 million hectares of land is severely affected by varied kind of land degradation (Space Application Centre, 2016). Therefore, in order to reverse the land degradation phenomenon, assessing the potential of a land in terms of its capability for a specific landuse is very essential. The land capability classification is considered as the prime prerequisite for planning and implementation of the natural resources conservation programs at watershed level. The land capability evaluation process evaluates the land units from general perspective irrespective of its use. The productivity potential and flexibility in cropping pattern are used to form the base of rating the Land Capability Classification. The Land Capability Classification (LCC) utilizes the physical nature ofthe land such as its geology, topography, soil, etc. and other miscellaneous factors suchas climate, erosional hazards and management practices for optimum and sustainable utilization of the land. On the basis of limitation and hazard occurring on a land the LCC can be further subdivided into Capability Class, Capability Sub Class and Capability Unit (Gad, 2015). The soil mapping units having comparable potential and continuing limitations are grouped to form capability units and they all have common land management requirements (Gad, 2015). The capability sub classes are group of capability units having special limitation such as erosion andrunoff (e), excess water (w), rooting zone limitation (s) and climatic limitation (c). The capability class is the broadest category of all which is a group of capability sub classes or capability units having similar degree of limitation or hazard. According to (USDA, 2019) classification, the capability classes are categorized into 8 classes; categories numbered in roman from I to VIII. Therefore, the land usability is defined by land capability rather than by the user (Panhalkar, 2011). The traditionalmethods of land capability mapping are tedious and time consuming. On the other hand, Geoinformation technology in association with remotely sensed data can provide ample of

${ }^{*}$ Corresponding Author - nitinchauhan.isro@hotmail.com

${ }^{1}$ Regional Remote Sensing Centre- West, ISRO Complex, Jodhpur, Rajasthan -342005 
opportunities to analyze different variables resulting in optimized land use management. Keeping in this view, the present study was taken to study the land capability assessment of Ghaggar river basin using integrated remote sensing and geographical information system approach according to land capability classification.

\section{MATERIAL AND METHODS}

For the current research, upper part of the Ghaggar river basin up to confluence of Medkhali river was studied. The study area extends from $76^{\circ} 51^{\prime} 45.06^{\prime \prime}$ and $30^{\circ} 36^{\prime} 46.50^{\prime \prime}$ to $77^{\circ} 12^{\prime} 45.30^{\prime \prime}$ and $30^{\circ} 54^{\prime} 27.18^{\prime \prime}$ and covers an area of $559.14 \mathrm{~km}^{2}$. The major soils of Ghaggar river basin are Dystric Eutrochrepts (10.48\%), Fluventic Ustochrepts (5.21\%), Typic Udorthents (37.62\%), Typic Ustifluvents (11.07\%), Typic Ustochrepts (3.46\%), Typic Ustorthents $(30.62 \%)$ and UlticUstochrepts $(1.54 \%)$. The agriculture is the prominent activity in the area and is the prime means of livelihood.The slope, soil depth, texture, stoniness; soil drainage condition and risk of soil erosion were used for Land Capability Classification. The slope and slope steepness and slope length factor in soil erosion revised universal soil loss equation (RUSLE), were calculated from Sentinel-1 interferometrically derived digital elevation model having spatial resolution of 13.92 meters. The soil depth, texture, drainage, soil erodibility (RUSLE) and stoniness were calculated from the National Bureau of Soil Survey and Landuse Planning $1: 5,00,000$ scale maps and NBSS Publications (Sachdev et al., 1995; Sidhu et al., 1997; Sidhu et al., 1995). The $C$ factor and $P$ Factor in RUSLE are calculated from Landuse Landcover map created from Landsat 8 satellite data having spatial resolution of 30 meter for the year 2015. These layers are overlaid in ArcGIS 10.5 using analysis tools to reveal different Land capability classes.

\section{RESULTS AND DISCUSSION}

\section{Soil and Slope Characteristics}

The land capability classification requires the analysis of morphological, physical and chemical characteristics and slope of the soil. The soils of the study area were physiographically divided into 4 regions (i) soils of Shivaliks hills, (ii) soils of Piedmont plains (iii) soils of old Alluvium plains, and (iv) soils of Active/Recent Flood plains. It is having 15 soil mapping units as classified from the soil maps.The soils of Shivaliks hills are moderately shallow to moderately deep and soils of piedmont plains; old alluvium plains and recent alluvium plains are deep. The texture of the Ghaggar river basin can be divided into clay loam, loam, sandy clay loam and sandy loam which contributes $0.75,51.4,5.2$ and $42.6 \%$,

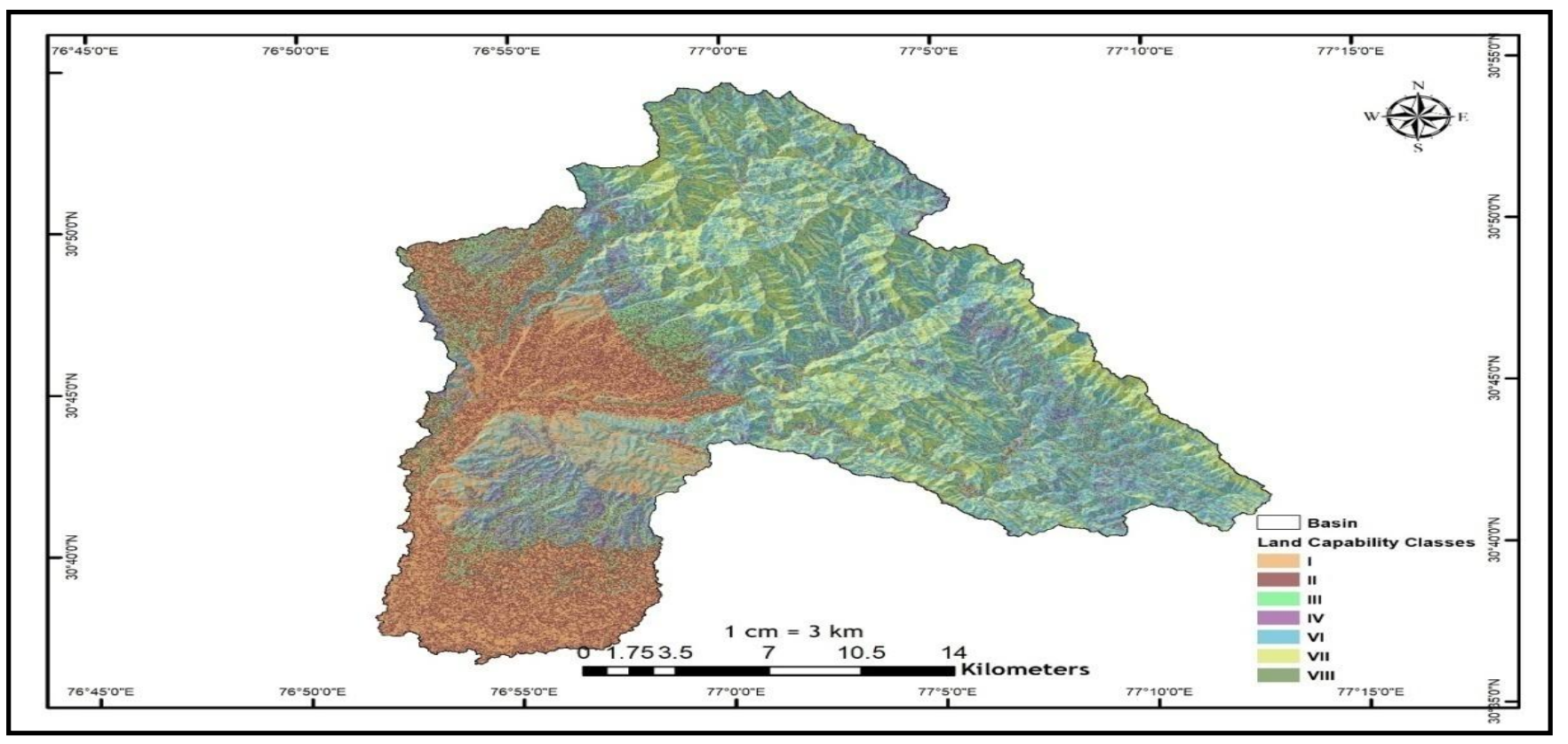

Fig. 1: Land capability classification of Ghaggar river basin 
respectively of the total study area.The soil drainage class prevailing in Ghaggar river basin comprises of moderately well drained, somewhat excessive drained and well drained classes occupying 5.2, 30.6 and $64.2 \%$, respectively. The study area is divided into three classes of stoniness i.e. nil to slight, moderate and strong accounting for $58.9,32.2$ and $8.89 \%$, of the study area, respectively. The mean annual rate of soil erosion in Ghaggar river basin ranges from 0 to $20119 \mathrm{t} \mathrm{ha}^{-1} \mathrm{y}^{-1}$. The Ghaggar river basin is prioritized into 5 zones based on the severity of the estimated rates of erosion. The percentage slope layer of Ghaggar river basin was classified into 6 classes i.e. 0 - 3, 3 - 8, 8 $15,15-30,30-50$ and $>50$ which are spatial distributed as 8.7, 15.2, 10.4, 19.5, 26.7 and $19.6 \%$, respectively in the study area.

\section{Land Capability Classification-Overlay Analysis}

The slope, soil depth, texture, stoniness, drainage and soil erosion extent were overlaid using the intersect operation available in ArcGIS
10.5 in order to obtain the various land capability categories as per guidelines provided by (USDA, 2019) (Fig. 1). The overlay analysis resulted in presence of seven land capability classes in the Ghaggar river basin. The land capability classes suitable for annual agriculture crops i.e. Class I IV (Atalay, 2016; Gad, 2015; Gashaw et al., $2017)$ accounted for $51.9 \%\left(290.23 \mathrm{~km}^{2}\right)$ of the total area of the basin. The limitations of this group include flat to moderately steep slope, deep to shallow soil depth, well to somewhat excessive drainage, stoniness and nil to slight erosion. The limitations increase while moving to class III and IV and therefore require better management as compared to class I and II. The class VI-VIII comprises of $48.1 \%\left(268.91 \mathrm{~km}^{2}\right)$ of the basin area and can be used for grazing, forestry, wildlife and woodland purposes (Atalay, 2016; Gad, 2015; Ayehu, 2013). These classes are affected with severe limitation such as steep slopes, severe to very severe erosion, stoniness, shallow depths. The areal distribution of the different land capability classes in Ghaggar river basin is shown inTable 1 .

Table 1:The areal distribution of Land Capability Classes in Ghaggar river basin

\begin{tabular}{cccc} 
Land Capability Class & Description & Area $\left(\mathrm{km}^{2}\right)$ & Percentage Area $(\%)$ \\
\hline Class I & & 83.02 & 14.85 \\
Class II & Suitable for annual crop & 84.81 & 15.17 \\
Class III & cultivation & 52.07 & 9.31 \\
Class IV & & 70.33 & 12.58 \\
Class VI & Suitable for grazing, forestry and & 149.13 & 26.67 \\
Class VII & wildlife & 114.67 & 20.51 \\
Class VIII & Not suitable for crop cultivation & 5.12 & 0.91 \\
Total & & 559.14 & 100 \\
\hline
\end{tabular}

The distribution of the current landuse as per the classification of Landsat OLI (Operational

Land Imager) satellite imagery of year 2015 is given in Fig. 2 and (Table 2).

Table2: The areal distribution of current land use (2015) of Ghaggar river basin

\begin{tabular}{l|c|c|}
\hline \multicolumn{1}{|c|}{ Landuse Categories } & Area $\left(\mathrm{km}^{2}\right)$ & Percentage Area (\%) \\
\hline Barren land & 0.13 & 0.0 \\
Built-Up Land & 52.44 & 9.4 \\
Cropland & 186.53 & 33.4 \\
Deciduous Broadleaf Forest & 163.76 & 29.3 \\
Evergreen Broad Forest & 33.77 & 6.0 \\
Mixed Forests & 35.44 & 6.3 \\
Shrubland & 53.12 & 9.5 \\
Wasteland & 3.10 & 0.6 \\
Waterbodies & 30.85 & 5.5 \\
Total & 559.14 & 100.0 \\
\hline
\end{tabular}


An attempt has been made to understand how the different landuse categories of the current landuse are distributed in the different land capability classes (Table 3 ). It is inferred from the analysis that $98.61 \mathrm{~km}^{2}(52.86 \%)$ of the current cropland is in land capability classrange of I to IV while $87.92 \mathrm{~km}^{2}(47.14 \%)$ of the cropland falls in Class VI to VIII.These results clearly indicate the landuse distribution of the current landuse in the Ghaggar river basin is not as per its capability which is affecting the environmental sustainability and deteriorating the agriculture productivity. The cultivated land in the Classes VI to VIII are responsiblefor severe to verysevere soil erosion. The other landuse classes such as built-up, deciduous broadleaf forest, evergreen forest, mixed forest, scrubland, wasteland and waterbodies are also present in Class I to IV accounting for $191.62 \mathrm{~km}^{2}$ (34.3\%). The landuse other than cropland in Class I to IV

Table 3: Areal distribution of current landuse in Land capability classes of Ghaggar river basin

\begin{tabular}{|c|c|c|c|c|c|c|c|c|}
\hline & \multicolumn{7}{|c|}{ Land Capability Classes } & \\
\hline Landuse 2015 & $\mathrm{I}$ & II & III & IV & $\mathrm{VI}$ & VII & VIII & Row Total $\left(\mathrm{km}^{2}\right)$ \\
\hline Barren land & 0.00 & 0.00 & 0.00 & 0.00 & 0.04 & 0.09 & 0.00 & 0.13 \\
\hline Built-up Land & 18.08 & 22.78 & 5.53 & 3.17 & 2.19 & 0.69 & 0.00 & 52.44 \\
\hline Crop land & 22.51 & 27.79 & 24.50 & 23.81 & 53.60 & 31.72 & 2.60 & 186.53 \\
\hline Deciduous Broadleaf Forest & 16.60 & 6.86 & 8.36 & 23.92 & 57.79 & 50.14 & 0.10 & 163.76 \\
\hline Evergreen Broad leaf Forest & 0.06 & 0.23 & 0.96 & 4.54 & 14.56 & 13.39 & 0.03 & 33.77 \\
\hline Mixed Forests & 1.63 & 1.95 & 3.26 & 5.42 & 10.69 & 10.63 & 1.85 & 35.44 \\
\hline Shrubland & 13.10 & 15.70 & 6.12 & 5.19 & 6.62 & 6.24 & 0.15 & 53.12 \\
\hline Wasteland & 0.82 & 1.09 & 0.03 & 0.10 & 0.34 & 0.34 & 0.38 & 3.10 \\
\hline Water bodies & 10.24 & 8.39 & 3.31 & 4.18 & 3.29 & 1.43 & 0.00 & 30.85 \\
\hline Column Total $\left(\mathrm{km}^{2}\right)$ & 83.02 & 84.81 & 52.07 & 70.33 & 149.13 & 114.67 & 5.12 & 559.14 \\
\hline
\end{tabular}

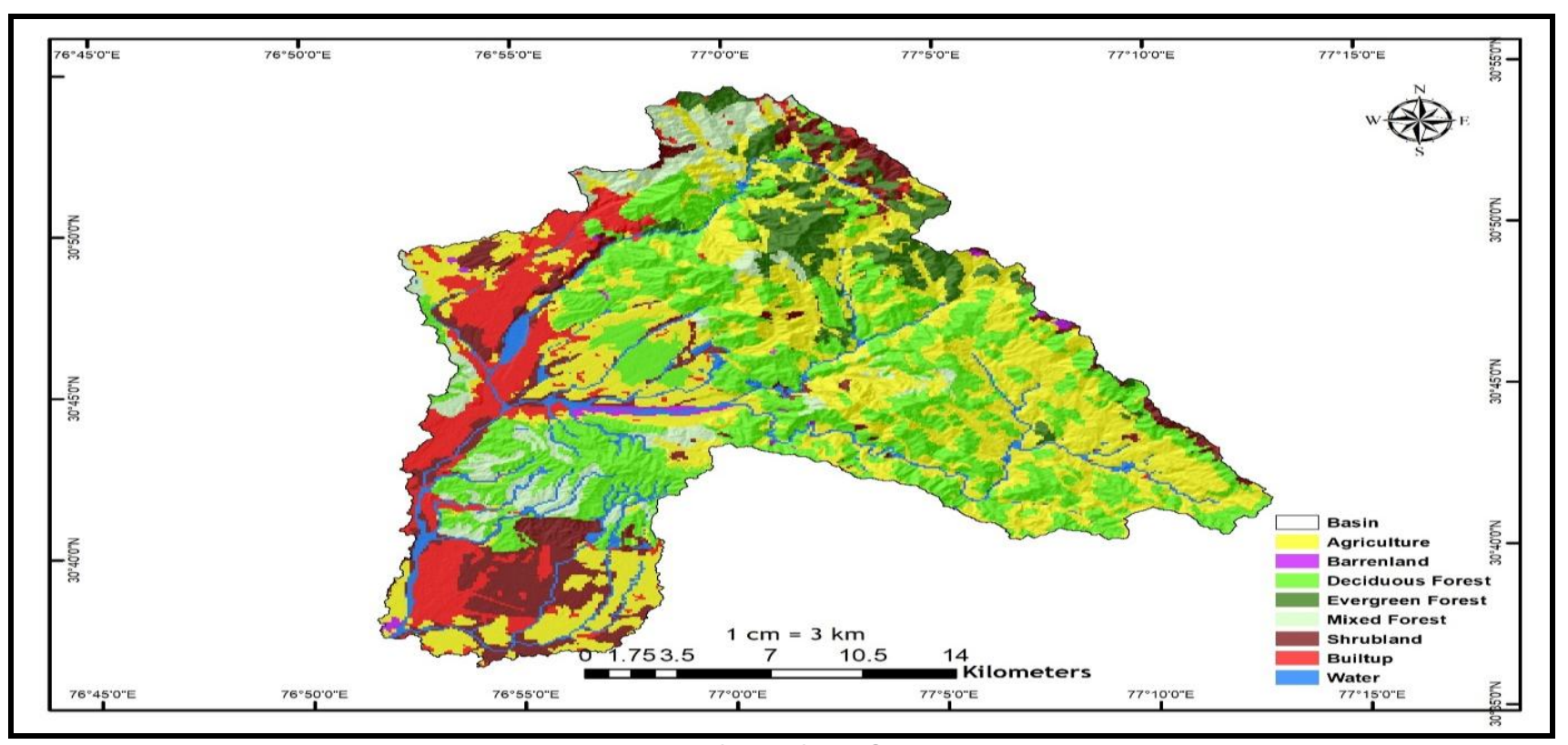

Fig.2: Landuse map (2015) of Ghaggar river basin

should have relocated to Class VI to VIII as per its capabilities providing more agriculturally suitable land. A comparative analysis conducted between the current cropland with the land's capability it was deduced that the capability of the land supporting agricultural activities is higher than the area which is currently under agriculture i.e. $214.54 \mathrm{~km}^{2}$ (Table 3) (except built-up and waterbodies) and $186.53 \mathrm{~km}^{2}$ (Table 2 ) respectively suggesting that there is potential in some areas which can be converted to cropland. This land capability classifications results in a new landuse plan for Ghaggar river basin (Fig. 3) based on the description of potential uses of the classes (Table 1). 


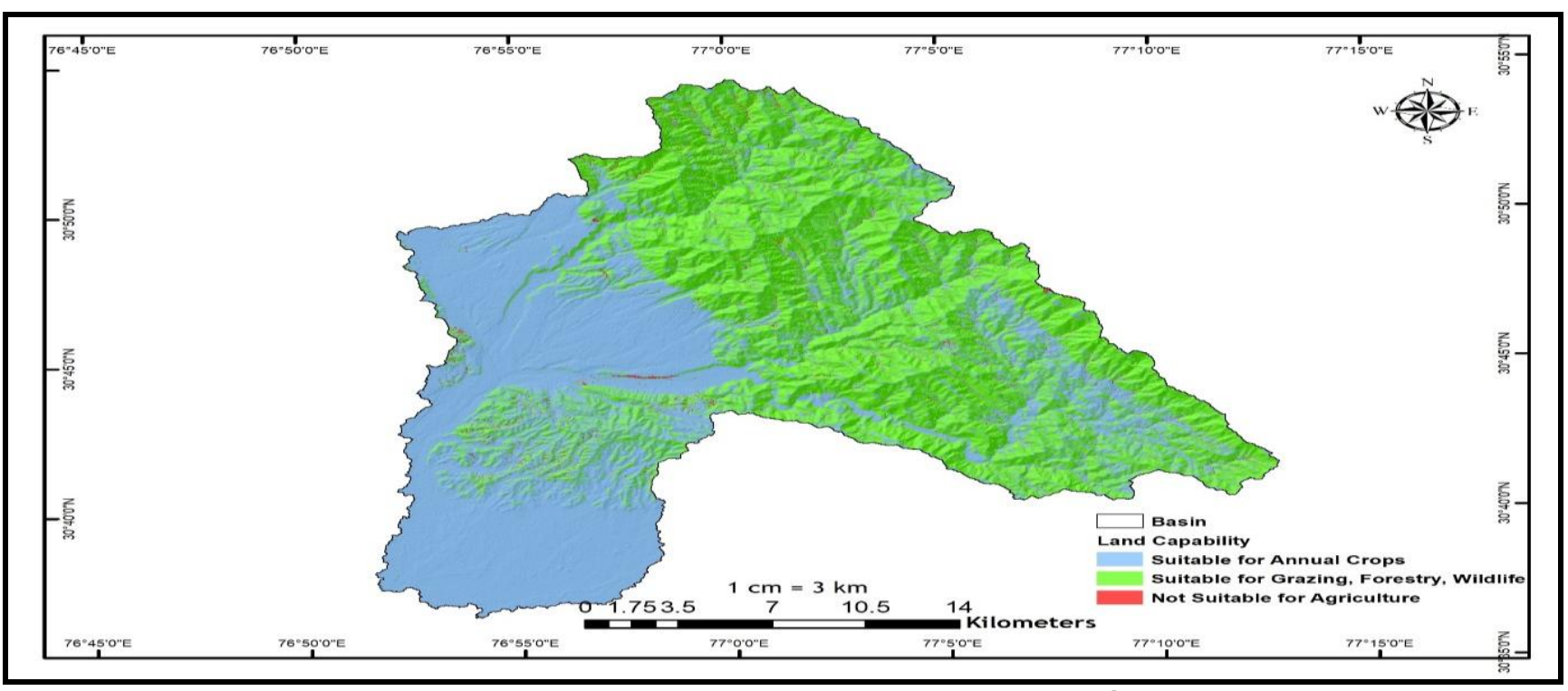

Fig. 3: The new landuse plan based on the land capability for Ghaggar river basin

In Ghaggar river basin the potential land capability for agriculture is $214.54 \mathrm{~km}^{2}$ while the current land under cultivation is $186.53 \mathrm{~km}^{2}$. It is further inferred from the results that $48.1 \%$ of the basin area falls in land capability classes $\mathrm{VI}$ to VIII which are unsuitable for agricultural activities due to presence of severe limitations such as steep slopes, poor drainage, excessive stoniness and very severe erosion risks. Conversely landuse such as forest, scrublands,

\section{REFERENCES}

Abate, S. (2011). Estimating soil loss rates for soil conservation planning in the Borena woreda of South Wollo highlands, Ethiopia. Journal of Sustainable Development in Africa, 13 (3), 87-106.

Atalay, I. (2016). A New Approach to the Land Capability Classification: Case Study of Turkey. Procedia Environmental Sciences, 32, 264-274.

Ayehu, G. T. (2013). Land Capability mapping with SPOT data and Geoinformation technology South Gondar, North-Western Highlands of Ethiopia. Second International Conference on AgroGeoinformatics (Agro-Geoinformatics) (pp. 255-259). Fairfax, VA: IEEE.

Biswas, S. S., \& Pani, P. (2015). Estimation of soil erosion using RUSLE and GIS techniques:a case study of Barakar River basin, Jharkhand, India. Modeling Earth Systems and Environment, 42 (1), 1-13. built-up are extended in category I to IV revealing that the landuse distribution in Ghaggar river basin is not as per its suitability. Therefore, it is highly imperative that the landuse should be allocated as per its capability taking into consideration the preventive measures to resolve the prevalent limitations.A new utilization plan as per the land capability has been suggested for Ghaggar river basin.

Gad, A. (2015). Land capability classification of some western desert Oases, Egypt, using remote sensing and GIS. Egyptian Journal of Remote Sensing and Space Sciences, 18, S9-S-18.

Gashaw, T., Tulu, T., \& Argaw, M. (2017). Erosion risk assessment for prioritization of conservation measures in Geleda watershed,Blue Nile basin, Ethiopia. Environmental Systems Research, 6 (1), 1-14.

Gibbs, H. K., \& Salmon, J. M. (2015). Mapping the world's degraded lands. Applied Geography, 57, 12-21.

Panhalkar, S. (2011). Land capability classification for integrated watershed development by applying remote sensing and GIS techniques. ARPN Journal of Agricultural and Biological Science, 6 (4), 46-55. 
Sachdev, C. B., Lal, T., Rana, K. C., \& Sehgal, J. (1995). Soils of Haryana: Their Kinds, Distribution, Characterization and interpretations for optimising Land Use. Nagpur: National Bureau of Soil Survey and Landuse Planning.

Scherr, S. J., \& Yadav, S. N. (1996). Land degradation in the developing world: implications for food, agriculture, and the environment to 2020. 2020 vision discussion papers 14, International Food Policy Research Institute (IFPRI) .

Sidhu, G. S., Rana, K. C., Sehgal, J., \& Velayutham, M. (1997). Soils of Himachal Pradesh: Their Kinds, Distribution, Characterization and interpretations for Optimising Land Use. Nappur: National
Bureau of Soil Survey and Landuse Planning.

Sidhu, G. S., Walia, C. S., Lal, T., Rana, K. C., \& Sehgak, J. (1995). Soils of Punjab: Their Kinds, Distribution, Characterizationa dn Interpretations for optimising Landuse. Nagpur: National Bureau of Soil Survey and Landuse planning.

Space Application Centre. (2016). Desertification and Land Degradation Atlas of India (Based on IRS AWiFS data of 2011-13 and 2003-05). Ahmedabad, India: Space Applications Centre, ISRO.

USDA. (2019). National soil survey handbook 430-VI. U.S. Department of Agriculture, Natural Resources Conservation Service. 